\title{
Alexander Weidner
}

\section{Das Ende Deuterojesajas}

Eine literarkritische und redaktionsgeschichtliche Studie zur Entstehung von Jes 40-60

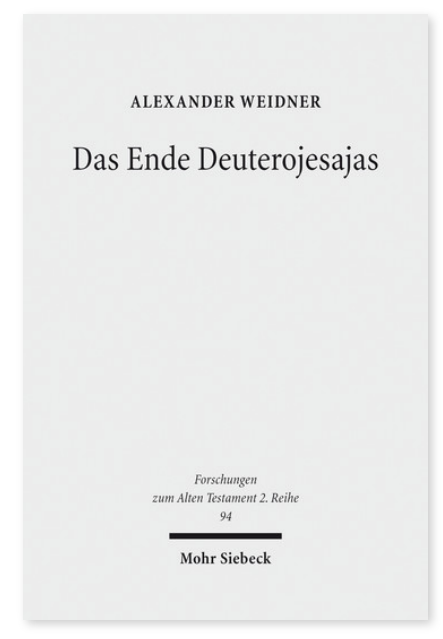

2017. XIV, 273 Seiten. FAT II 94

ISBN 978-3-16-155396-7

DOI 10.1628/978-3-16-155396-7 eBook PDF $94,00 €$

ISBN 978-3-16-155395-0

fadengeheftete Broschur 94,00€
Seit Bernhard Duhm hält man Jes 55 entweder für das Schlusskapitel Deuterojesajas oder das einer Fortschreibung. In letzter Zeit wurde dagegen jedoch vermehrt und von unterschiedlicher Seite Einspruch erhoben. Alexander Weidner zeigt, dass dieses Kapitel eine Brücke zwischen Jes 54 und Jes 60 bildet, aber tatsächlich jünger als diese beiden Kapitel ist. Ausgehend von Kap. 55 wird vornehmlich das Werden von Jes 40.46-55.60 in den Blick genommen. Der Kern Deuterojesajas bestand in Jes 40,12-46,11*. Jes 48,20 wird dabei für erheblich jünger gehalten. Außerdem zeigt der Autor, dass besonders die Kapitel 40.48-52.54f. eine vielschichtige Entstehungsgeschichte hinter sich haben. Ein abschließender Blick auf die Septuaginta lehrt, dass diese in vielen Fällen nicht als ungenaue Übersetzung zu gelten hat, sondern die Stellen, an denen die moderne Literarkritik ansetzt, nicht nur wahrnimmt, sondern auch bewusst glättet.

Alexander Weidner Geboren 1984; 2004-09 Studium Lehramt Gymnasium Latein und Ev. Religion; 2009-13 wissenschaftlicher Mitarbeiter an der Friedrich-Schiller-Universität Jena; 2013-15 Referendariat; seit 2015 Studienrat an der KGS Salzhemmendorf.

Jetzt bestellen:

https://mohrsiebeck.com/buch/das-ende-deuterojesajas-9783161553967?no_cache=1

order@mohrsiebeck.com

Telefon: +49 (0)7071-923-17

Telefax: +49(0)7071-51104 